\title{
The effect of sea surface temperature on the structure and connectivity of species landings interaction networks in a multispecies recreational fishery
}

\author{
Kayla M. Blincow and Brice X. Semmens
}

\begin{abstract}
Multispecies fisheries, particularly those that routinely adapt the timing, location, and methods of fishing to prioritize fishery targets, present a challenge to traditional single-species management approaches. Efforts to develop robust management for multispecies fisheries require an understanding of how priorities drive the network of interactions between catch of different species, especially given the added challenges presented by climate change. Using 35 years of landings data from a southern California recreational fishery, we leveraged empirical dynamic modelling methods to construct causal interaction networks among the main species targeted by the fishery. We found strong evidence for dependencies among species landings time series driven by apparent hierarchical catch preference within the fishery. In addition, by parsing the landings time series into anomalously cool, normal, and anomalously warm regimes (the last reflecting ocean temperatures anticipated by 2040), we found that network complexity was highest during warm periods. Our findings suggest that as ocean temperatures continue to rise, so too will the risk of unintended consequences from single-species management in this multispecies fishery.
\end{abstract}

Résumé : Les pêches plurispécifiques, plus particulièrement celles qui ajustent régulièrement le moment, le lieu et les méthodes de pêche pour prioriser différentes cibles, constituent un défi pour les approches de gestion monospécifique traditionnelles. L'élaboration de méthodes de gestion robustes pour les pêches plurispécifiques nécessite une compréhension de l'incidence des priorités sur le réseau d'interactions entre les prises de différentes espèces, particulièrement au vu des autres défis présentés par les changements climatiques. En utilisant 35 années de données de débarquements pour une pêche sportive dans le sud de la Californie, nous tirons parti de méthodes empiriques de modélisation dynamique pour construire des réseaux d'interactions causales entre les principales espèces visées par la pêche. Nous relevons des preuves solides de dépendances entre les séries chronologiques de débarquements par espèce modulées par des préférences hiérarchiques apparentes en matière de prises dans cette pêche. En classant les séries chronologiques de débarquements selon qu'elles témoignent de régimes anormalement froids, normaux ou anormalement chauds (ces derniers reflétant les températures des océans projetées en 2040), nous constatons en outre que la complexité des réseaux est maximum durant des périodes chaudes. Nos constatations donnent à penser que la poursuite du réchauffement des océans sera accompagnée d'une augmentation du risque de conséquences imprévues de la gestion monospécifique dans cette pêche plurispécifique. [Traduit par la Rédaction]

\section{Introduction}

As the name suggests, a multispecies fishery is a single fishery that targets multiple species. Such fisheries, especially those that readily adapt their fishing strategy to prioritize different species targets, can create complex interactions between species landings that are difficult to account for using traditional single-species assessments (Murawski 1991; Thorpe et al. 2016; Vinther et al. 2004). In recent decades, researchers and managers have developed a number of novel modelling techniques and expanded management frameworks to address some of the difficulties that can arise from applying single-species tools to multispecies fisheries (e.g., Vinther et al. 2004; Ulrich et al. 2011; Plagányi et al. 2014; Thorpe et al. 2016; Nielsen et al. 2018). Despite these advances, many challenges remain when it comes to multispecies fisheries. One such challenge is the ability to quantify and describe the complex dependencies that can be created between species landings. Moreover, given the influence of climate change on ocean ecosystems, efforts to understand how future ocean conditions will mediate such dependencies is an important part of planning for resilient fisheries.

Climate change presents a formidable challenge across disciplines and sectors globally, impacting everything from crop yields (Campbell et al. 2016; Kukal and Irmak 2018), to the frequency of disease outbreaks (Caminade et al. 2019; Wu et al. 2016), to fisheries yields (Free et al. 2019; Weatherdon et al. 2016). The impact of climate change on social-ecological systems, or systems in which humans and nature interact (e.g., fisheries), can be especially difficult to predict as they constitute a complex network of social, environmental, and economic interactions (Folke 2006; Garmestani et al. 2019; Miller et al. 2010). Yet, understanding and predicting climate induced shifts in social-ecological systems, including fisheries, is a critical part of efforts to maintain productivity and protect livelihoods.

One of the hallmark effects of anthropogenic climate change is a global increase in sea surface temperature (SST) (Rayner et al.

Received 10 April 2021. Accepted 10 December 2021.

K.M. Blincow. Scripps Institution of Oceanography, University of California San Diego, La Jolla, CA 92093, USA; Center for Marine and Environmental Studies, University of the Virgin Islands, St. Thomas, USVI 00802, USA.

B.X. Semmens. Scripps Institution of Oceanography, University of California San Diego, La Jolla, CA 92093, USA.

Corresponding author: Kayla M. Blincow (email: kaylamblincow@gmail.com).

(C) 2022 The Author(s). This work is licensed under a Creative Commons Attribution 4.0 International License (CC BY 4.0), which permits unrestricted use, distribution, and reproduction in any medium, provided the original author(s) and source are credited. 
Fig. 1. Visualization of the conceptual framework of our analysis. Black arrows depict the flow of logic between the different components of the analysis (described below). Gray arrows depict the connection between warm sea surface temperature (SST) anomalies and the corresponding subsets of the landings time series associated with those anomalies. The white arrow depicts the collection of the landings time series into the convergent cross-mapping analysis (CCM). Landings time series from a fishery are the result of a combination of interacting factors that influence how Commercial Passenger Fishing Vessel (CPFV) captains choose to target different species. These factors can be environmental, social, or regulatory. To identify how a specific factor, warm SST, influences the causal interaction network of species landings, we filtered our landings time series based on that factor of interest. We then used CCM to identify causal relationships between those filtered species landings and construct the interaction network. By comparing interaction networks under different SST conditions, we can gain insight into how SST influences the underlying landings connectivity in this fishery.

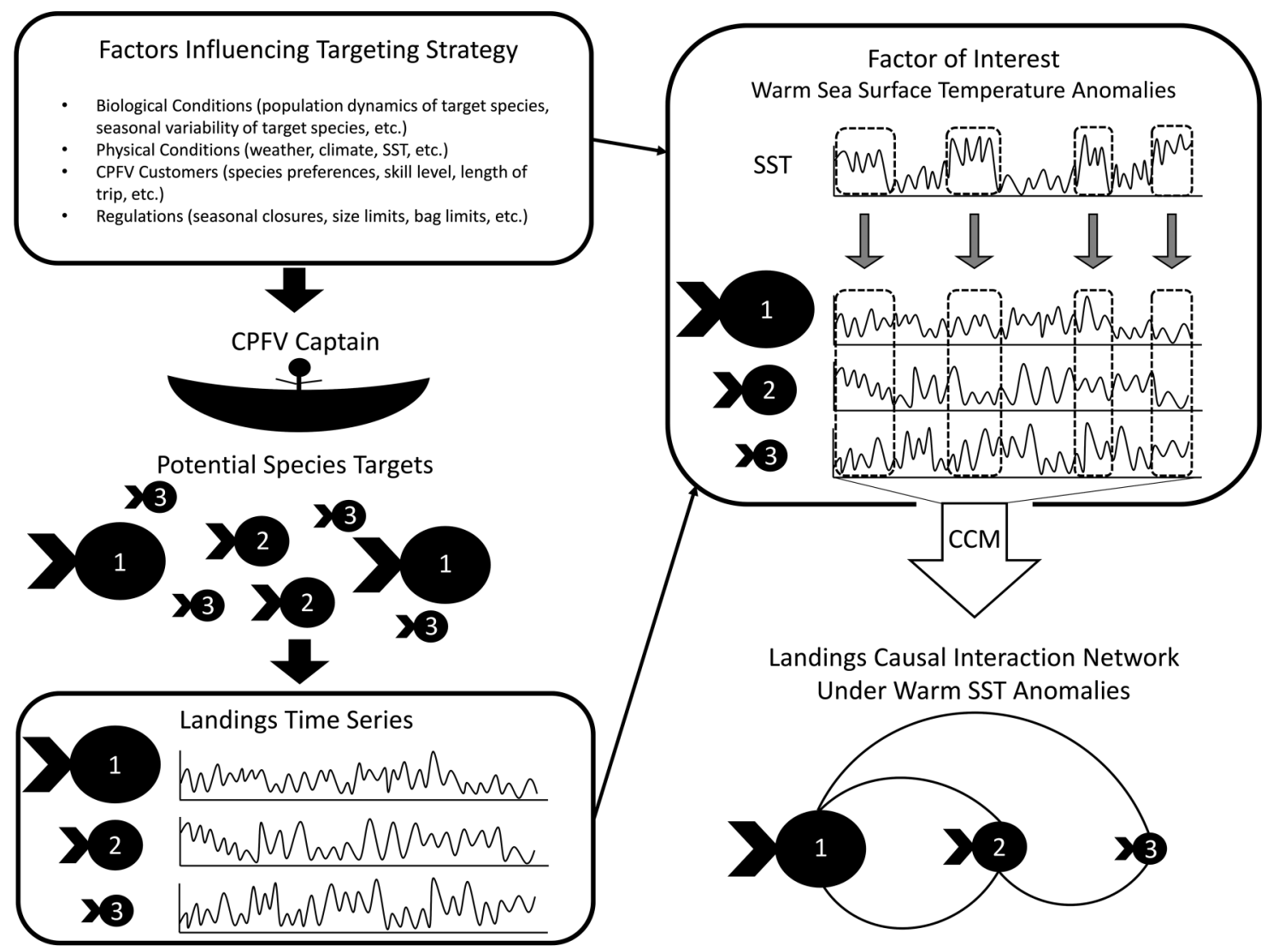

2003; Weatherdon et al. 2016). In this study we used catch data from a multispecies fishery to construct causal networks of species landings under different SST conditions to better understand differences in landings network structure and complexity under different ocean temperature scenarios. A visual representation of the conceptual framework of our analysis is provided in Fig. 1. The basis of our approach lies in the understanding that by identifying relationships between the landings of different species targeted by the same fishery, we can gain insight into the extent to which shifts in the landings of one species can influence the landings of other species. We can compile these relationships to build networks of causal interactions between landings of species targeted by the same fishery. This is useful, because fisheries landings data are a representation of all the upstream processes that influence species-specific catch including, but not limited to, fisher preference, regulations, population dynamics, and environmental variability. By grouping landings based on an upstream process of interest, regional SST in our case, it is possible to see how that process influences the causal landings network, which in turn provides insight into the responses of the fishery as a whole to that process. If the underlying landings network responds to regional SST changes by becoming more complex and connected, processes that influence the landings of a single species, such as regulatory changes, are more likely to have unintended effects on other species targeted by the same fishery.

To identify causal relationships between landings time series we employed empirical dynamic modelling (EDM), a nonlinear time series analysis method. This approach draws from Takens' theorem, which posits that you can reconstruct the manifold of a chaotic dynamical system by lagging a time series of a variable from that system across the appropriate dimensions (Deyle and Sugihara 2011; Takens 1981). Convergent cross-mapping (CCM) uses this theorem as a basis to test for causal relationships between variables from the same system by determining the extent to which the time series of one variable can estimate states of the other (Sugihara et al. 2012). By applying CCM to catch time series, we were able to explicitly describe the underlying structure of a multispecies fishery by constructing networks of causal interactions between the landings of different fishery species.

We chose to investigate the southern California Commercial Passenger Fishing Vessel (CPFV) fishery as our case study. This is a multispecies recreational fishery that constitutes an important part of the economy and culture of southern California (Bellquist et al. 2017; Bellquist and Semmens 2016; Jarvis et al. 2004; Schroeder and Love 2002; Weber and Heneman 2000). It is important to note that since this is a recreational fishery and fishers are not selling their 
catch, the relative perceived value (hereinafter referred to as "value") of different species is based on the collective preferences of the recreational angling community. The CPFV fleet is made up of charter sport fishing vessels that typically take groups of 30-50 anglers on fishing trips in the inshore and offshore waters of southern California and northern Baja California, Mexico (Bellquist et al. 2017; Parnell et al. 2010). CPFV captains account for the desires and skill level of their patrons, environmental variables, and sport fishing regulations to decide which species are the best targets for any given trip. As a consequence of these decisions, species that are not necessarily biologically or ecologically connected become linked through their fishery landings. For example, the seasonal emergence of warmwater species in summer months and regulation changes limiting harvest of one or more species have resulted in shifting species targets and, ultimately, shifts in landings (Dotson and Charter 2003; Bellquist and Semmens 2016). It seems reasonable to conjecture that climate driven shifts in SST would similarly reorganize the landings interaction network of the southern California CPFV fishery.

California's Fourth Climate Change Assessment states that, based on climate model predictions, SST in the region of our case study will increase $\sim 0.5$ to $1.5^{\circ} \mathrm{C}$ by 2040 and 2 to $4{ }^{\circ} \mathrm{C}$ by 2100 (Sievanen et al. 2018). CPFVs are known to show seasonal variation in species landings, in part due to changes in SST that mediate the presence of transient, often high value species, such as tuna species (Dotson and Charter 2003; Parnell et al. 2010). However, it is less clear how sustained (cross-season) SST changes resulting from climate change will influence the interactions between species landings. To isolate how the complexity of such landings interaction networks might change under different SST regimes, we built our networks after first grouping the landings time series into cool, normal, and warm regimes based on past regional SST anomalies. We reasoned that the dynamics present during anomalously warm periods, in particular, would provide insight into what we might expect from future CPFV species landings interactions given climate change. The networks we created inherently account for the complex dynamics associated with management action, fisher behavior, environmental variability, and every other factor influencing the fishery, because they rely on landings data that are influenced by all these things. Using these species landings networks, we identified and highlighted potential challenges to the resilience and management of the southern California CPFV fishery.

\section{Methods}

\section{Data}

We used California Department of Fish and Wildlife (CDFW) CPFV logbook data for this analysis. These data constitute daily trip records from CPFVs, including information on the date of fishing, trip length, port code or town of landing, and the CDFW fishing blocks fished (10-minute latitude by 10-minute longitude). Landings are recorded as the number of fish kept by species per trip. It should be noted that the logbook data do not necessarily represent a census of landings from the CPFV fishery due to log noncompliance by captains; however, logbook landings are consistent with other catch reports from this fishery, including reports to newspapers for advertising purposes, and the logbook data are frequently used as the primary source of data for investigating trends in the CPFV fishery (Bellquist et al. 2017; Dotson and Charter 2003; Hill and Barnes 1998). While CPFV logbook data were available from 1980 to 2017, to perform our analysis it was necessary to limit our time series to the extent of our available SST data (1983-2017).

The species frequently targeted by CPFVs vary across the California coast (Dotson and Charter 2003). To account for this, we filtered the logbook data based on regional classifications of the CPFV fleet made in Dotson and Charter (2003) to only include ports south of San Clemente, California (Fig. 2). By limiting our analysis to this region, we were able to limit the number of species groups targeted by the fleet. Based on our region of interest, we selected six species and species complexes for our analysis: rockfish species (Sebastes spp., Sebastidae), kelp bass (Paralabrax clathratus, Serranidae), barred sand bass (Paralabrax nebulifer, Serranidae), yellowtail (Seriola lalandi, Carangidae), Pacific bonito (Sarda leneolata, Scombridae), and tuna species (Thunnus spp., Scombridae). We selected barred sand bass and kelp bass because they are the most important recreational species in the region based on the number of fish taken and the relative importance placed on them by the CPFV fleet (Bellquist et al. 2017; Dotson and Charter 2003; Jarvis et al. 2014). Pacific bonito and rockfish species account for the second and third largest percentages of total landings, respectively, after bass species (Dotson and Charter 2003). We selected tuna species and yellowtail because, based on weight, they are among the largest recreational harvests in California and are especially important in the southern-most region (Dotson and Charter 2003). For the rockfish group, we compiled the landings of all Sebastes spp. represented in the data. For the tuna group, we compiled landings of the three most commonly caught tuna species in southern California: albacore (Thunnus alalunga, Scombridae), yellowfin tuna (Thunnus albacares, Scombridae), and Pacific bluefin tuna (Thunnus orientalis, Scombridae).

Different vessels in the CPFV fleet have different strategies for targeting fish (Bellquist et al. 2017). Some vessels only target high value species typically found farther offshore, while others exclusively fish nearshore (Bellquist et al. 2017). To avoid potential biases associated with different targeting strategies, we filtered the data to include only those vessels that interact with the full suite of species groups we identified by targeting both nearshore and offshore species. We began with 428 possible vessels that originated from ports south of San Clemente. To identify which of these vessels targeted both nearshore and offshore species we determined the top 10 most-landed species for each vessel and evaluated them for the presence of our species groups. If a vessel did not capture any of our species groups, we excluded it. For the remaining vessels, we then determined whether nearshore and offshore CDFW fishing blocks accounted for the bulk of each vessel's landings to confirm that the vessel was interacting with areas associated with each of our species groups. Nearshore fishing blocks included all blocks that touched the mainland coast. With the exception of the blocks along the coast of offshore islands, the rest of the fishing blocks were classified as offshore. We evaluated vessels that frequently targeted fishing blocks associated with offshore islands on a case-by-case basis as captains will often opportunistically target high value offshore species while transiting to the islands to target more nearshore associated species. If a vessel did not chiefly target members of our species groups, solely targeted nearshore, or solely targeted offshore fishing blocks, we did not include them in the analysis. This resulted in a total of 270 vessels out of the 428 possible from our selected region. After selecting vessels, we summed the landings of our six species groups from these vessels and created a daily landings time series for each group spanning from 1983 to 2017 (Fig. 3). For the species complexes, rockfish species and tuna species, we pooled the landings for the species included in those groups (group composition specified above). For the construction of the interaction networks, we limited our time series to the main fishing season of March through October. Note that our EDM analysis methods are robust to time gaps (described below).

We used the National Oceanic and Atmospheric Administration's (NOAA) Optimum Interpolation Sea Surface Temperature (OISST) data to classify the years in the CPFV landings time series based on SST. These data interpolate observations from satellites, ships, buoys, and Argo floats to create a map of daily SST at a resolution of $1 / 4^{\circ}$ and were provided by the NOAA-Ocean and Atmospheric Research-Earth System Research Laboratories Physical Sciences Laboratory (NOAA/OAR/ESRL PSL), Boulder, Colorado, USA, from their website at https://psl.noaa.gov/ (Reynolds et al. 2007). For this analysis, we selected SST data from a grid of the Southern 
Fig. 2. Map of the southern California study area. The main map depicts the study region, while the inset map above places the study region in the context of the larger region of continental North America. The ports that vessels were drawn from are shown by the solid black dots. The open circles show the central area of the California Department of Fish and Wildlife (CDFW) fishing blocks that had at least 100 trips throughout the CPFV logbook data time series, and the size of the circle is indicative of the total number of trips taken to that fishing block. The circle with the star is a fishing block that aggregates all fishing activity in Baja California, Mexico, outside of the nearshore ports north of Rosarito. The black bounding box shows the region where sea surface temperature data were derived. The base map used in both the main and inset maps is plotted using a Cartesian coordinate system with a fixed aspect ratio of 1.2 and was drawn from the worldHires dataset from the "mapdata" package in R, which was derived from the CIA World Data Bank (Becker et al. 2018).

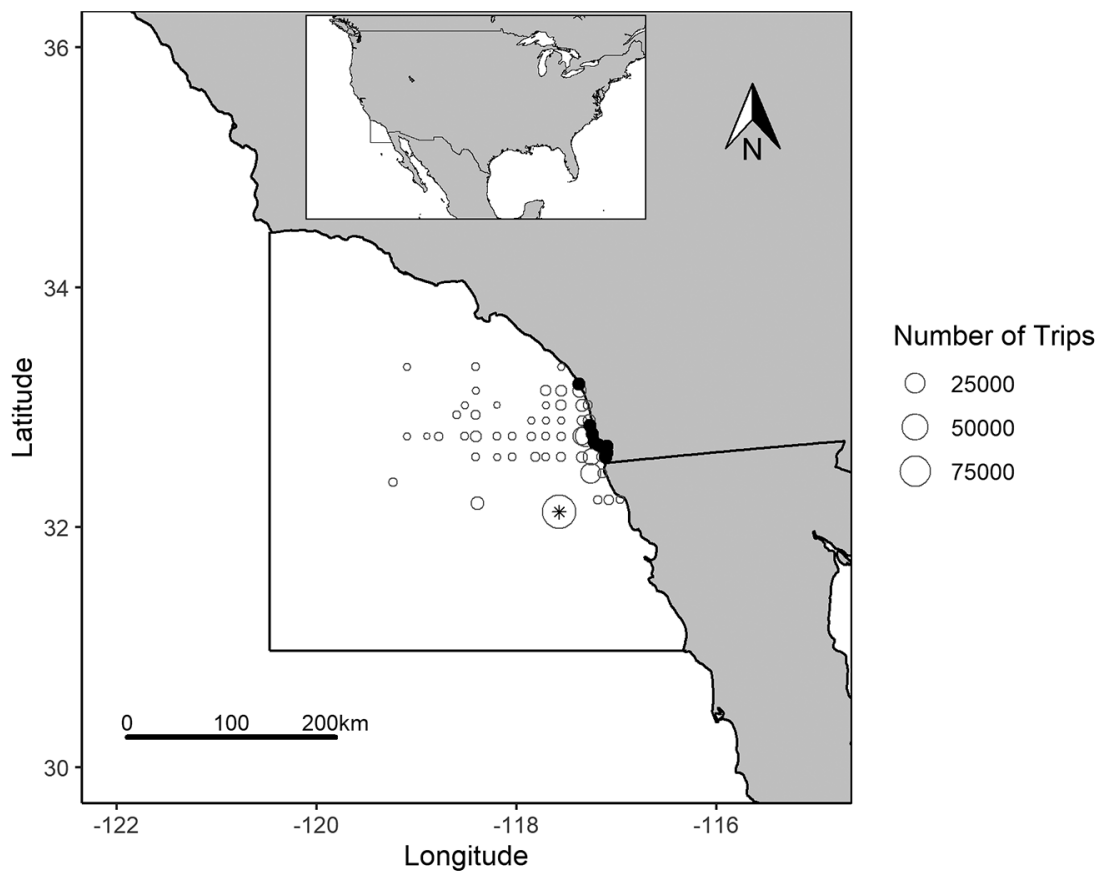

California Bight ranging from Point Conception, California, USA, to Punta Colonet, Baja California, Mexico (Fig. 2). We classified each year from our time series as "anomalously warm", "anomalously cool", or "normal". To do so, we first removed seasonal temperature effects by standardizing our SST data by calculating monthly temperature anomalies, subtracting the mean and dividing by the standard deviation of the monthly SST for each observation of SST within each month. We then calculated a three-month rolling mean of the daily SST anomalies across the temperature time series. We classified any year that had a three-month rolling mean that exceeded one standard deviation from the mean at any point during the year as "anomalously warm" in the positive direction and "anomalously cool" in the negative direction (Fig. 4). We classified the remaining years as "normal". There were no instances where a year met the conditions for more than one SST category. We explored other SST classification methods, such as classifying years based on recorded El Nino Southern Oscillation (ENSO) events and found that our results were generally robust to different methods of classification. We ultimately chose to classify years using the methods described because they more accurately represented regional SST anomalies in our southern California study area than other commonly used classifications.

We performed all analyses using $\mathrm{R}$ statistical software, version 3.6.1 ( $\mathrm{R}$ Core Team 2019). The code for our analyses can be found at https://github.com//kmblincow/CPFVs_CCMandSST (or via Zenodo at https://zenodo.org/record/5801863\#.YkytJNvMKCg).

\section{Convergent cross-mapping}

We tested for causal relationships between the landings of each of our species groups using convergent cross-mapping (CCM). CCM is a nonparametric method for identifying causal relationships in nonlinear dynamic systems (Sugihara et al. 2012). Given two time series, $X$ and $Y, C C M$ tests for causation by determining the extent to which the historical record of the values of $Y$, the predictor variable, can reliably estimate corresponding time points of $X$, the target variable (Sugihara et al. 2012). If $X$ causally influences $Y$, it is possible to reconstruct system states of $X$ from $Y$, because $Y$ is inherently dependent on the dynamics of X (Sugihara et al. 2012; Ye et al. 2015). As a result of this logic, the directionality of causation ( $X$ causes $Y$ ) is the opposite of the directionality of prediction across time series ( $Y$ predicts $X$ ). It is important to note that causal networks built from multiple time series can be transitive; if $X$ causes $Y$ and $Y$ causes $Z$, it follows that $X$ and $Z$ will also display a causal relationship (Sugihara et al. 2012). CCM detects these types of transitive causal relationships as well. For a more in-depth explanation and discussion of how CCM is able to distinguish causal relationships from correlative ones, see Sugihara et al. (2012).

We used the rEDM package (version 0.7 .5 ) to carry out our CCM analyses (Ye et al. 2021). After classifying each year based on SST, we subset and grouped the species landings time series based on these classifications. We performed CCM on every possible pairing of our species groups using daily landings time series from the main fishing season for all the years within each SST classification. CCM allows for the use of nonconsecutive time series when constructing manifolds through specification of separate but linked libraries from each SST period of paired time series. This allowed us to build networks representing the main fishing season for all the years in each SST classification despite the fact they did not constitute a continuous time series. Similar to the temperature time series, we scaled our landings data (full time series) by subtracting the mean and dividing by the standard deviation for each observation.

We specified a time interval of delay (tau, $\tau$ ) of one day for all our cross-maps. For each cross-map we used simplex projection 
Fig. 3. Landings time series (1983-2017) for each species group: $\mathrm{RF}=$ rockfish species, $\mathrm{KB}=$ kelp bass, $\mathrm{SB}=$ barred sand bass, $\mathrm{BO}=\mathrm{Pacific}$ bonito, $\mathrm{YT}=$ yellowtail, $\mathrm{TU}=$ tuna species.
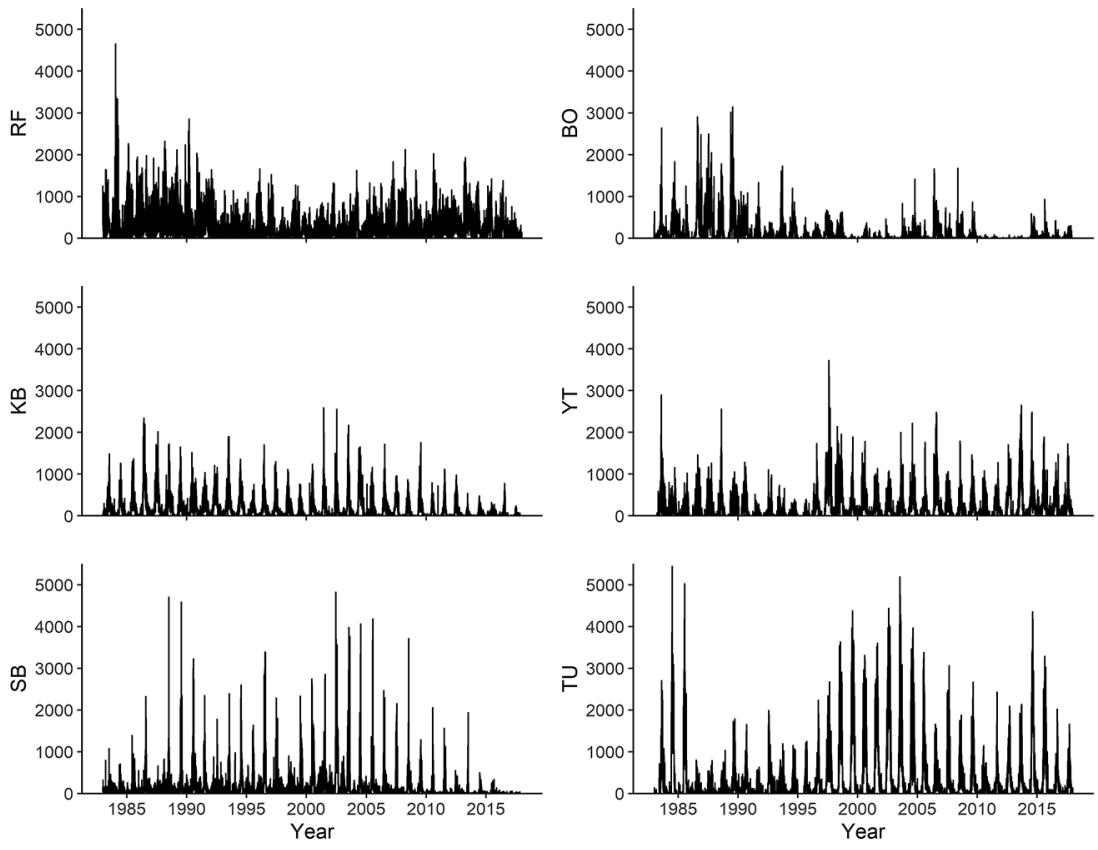

Fig. 4. SST time series (1983-2017) standardized to depict monthly anomalies. Light gray lines depict the daily SST monthly anomalies. The solid black line depicts the three-month rolling mean of the daily SST monthly anomalies. The dashed horizontal lines depict one standard deviation above and below the mean. We classified years as anomalously cool if the three-month rolling mean exceeded one standard deviation below the mean at any point during the year (marked with rectangles below the mean) and as anomalously warm if the three-month rolling mean exceeded one standard deviation above the mean (marked with rectangles above the mean). All other years are classified as normal. [Colour online.]

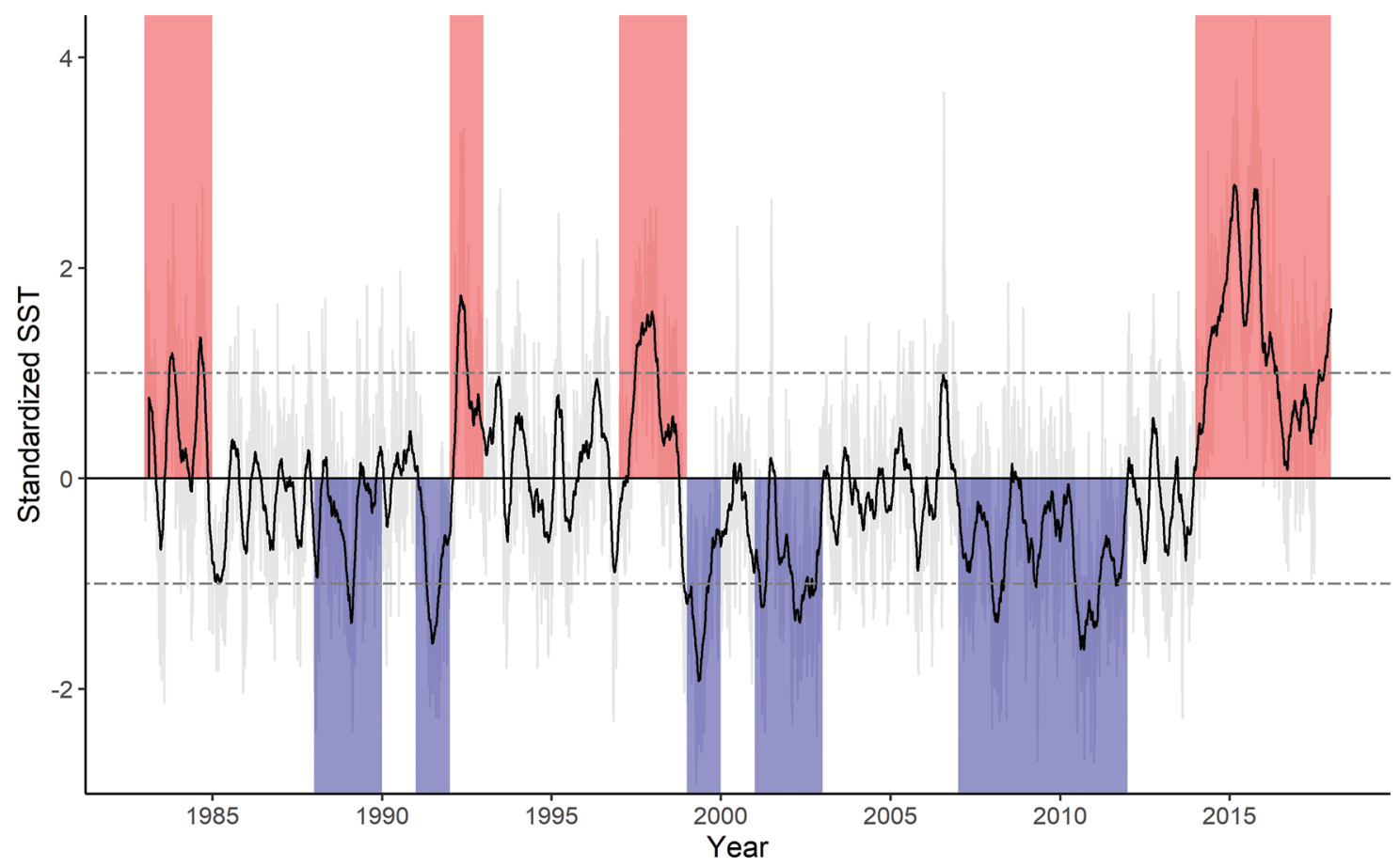

to identify the optimal embedding dimension (Sugihara et al. 2012; Sugihara and May 1990). We tested embedding dimensions ranging from 2 to 20 and selected the dimension that had the highest out-of-sample forecast skill for each species group in each temperature classification (Ushio et al. 2018). After selecting the optimal embedding dimension, we confirmed that each time series displayed a decay in forecast skill with time to prediction using the simplex projection. During cross-mapping we used the 
optimal embedding dimension that we identified for the predictor time series in all pairings. We provided the values for the optimal embedding dimensions for the predictor time series from each SST classification in Supplementary Table $S 1^{1}$.

An important determinant of causation using CCM is that the cross-map strength or forecast skill increases as more time points from the predictor time series are included in the analysis, known as convergence. We used Pearson's correlation coefficient (rho, $\rho$ ) to measure relative forecast skill, or the relative strength of the causal effect between the two cross-mapped landings time series (Sugihara et al. 2012). CCM generates a vector of rho values as the library of time points included increases allowing for assessment of convergence by evaluating whether rho increases as well. We tested library sizes ranging from one time point to the full predictor time series increasing in increments of 245 days for each SST classification. We tested the forecast skill of each library size at predicting every time point in the target time series for each SST classification. We generated plots of the forecast skill across all target time points of each library size to evaluate convergence (Supplementary Figs. S1 $a-1 c^{1}$ ). For all relationships that showed convergence, we selected the rho value at the maximum library size as our basis for significance testing and construction of interaction networks (see below).

Due to the seasonal nature of the landings time series, it is critical to distinguish between seasonal correlation effects and true causal effects. To test the significance of the causal relationships we observed, we used a seasonal surrogate test (Deyle et al. 2016). To perform this test, we cross-mapped every predictor time series (each species landings time series within each SST classification) against 500 surrogate time series that preserved the seasonality of the original target time series but with randomized anomalies by computing the mean seasonal trend over the specified time period then shuffling the residuals. We estimated $p$ values by calculating what percentage of the surrogate rho values exceeded the rho value from the maximum library size from the true crossmap results. If the rho value at the maximum library size was greater than the rho value at the 95th percentile of the surrogate time series samples $(p<0.05)$, then we concluded that there was a causal interaction between the two landings time series in question. We subsequently constructed interaction networks between species landings for each SST classification based on the relationships we identified as significant. We provided plots of the results of our seasonal surrogate testing in the supplementary material (Supplementary Figs. S $2 a-2 c^{1}$ ).

\section{Network analysis}

Networks are often visualized using nodes (depictions of unit of interest) and edges (visualizations of the relationship connecting the nodes) (Proulx et al. 2005). In our case our nodes are our landings time series for each species group and our edges are the causal relationships we found between the landings time series using CCM. Networks can also be directed or undirected (Proulx et al. 2005). A directed network has edges that incorporate directionality depicting which node is influencing the other in any given relationship in the network (Proulx et al. 2005). Our network is directed because our causal relationships display directionality. Additionally, network edges can be weighted, meaning the relationships between nodes can carry some value (Opsahl et al. 2010). In our case, our edges are weighted by the strength of the causal relationship detected by the CCM analysis (rho at maximum library size). There are mathematical tools and techniques (i.e., network analysis tools) that are used to describe the structure and connectivity of relationships between the nodes and edges of a network (Proulx et al. 2005).
We used two network analysis metrics, network density and degree centrality, to quantitatively characterize the structure of the interaction networks that resulted from the CCM analysis. Network density is the ratio of the number of direct connections in a network to the total number of direct connections possible and indicates the overall complexity of causal interactions in the network. Degree centrality is a metric that classifies nodes of a network based on how connected they are relative to other nodes. High-degree centrality indicates greater connectivity of a node, or network, when considering centrality of all nodes. As a result, networks with higher overall degree centrality are generally more complex. We used the degree centrality metric for directed and weighted networks put forth in Opsahl (2010), which accounts for the number of connections (i.e., edges) a node has, as well as the weights associated with those connections (in our case the strength of the causal interaction):

$$
\begin{aligned}
& C_{D-\text { in }}^{w \alpha}(i)=k_{i}^{\text {in }} \times\left(\frac{s_{i}^{\text {in }}}{k_{i}^{\text {in }}}\right)^{\alpha} \\
& C_{D-\text { out }}^{w \alpha}(i)=k_{i}^{\text {out }} \times\left(\frac{s_{i}^{\text {out }}}{k_{i}^{\text {out }}}\right)^{\alpha}
\end{aligned}
$$

where degree centrality in (eq. 1 ) or out (eq. 2) of a node (i) is $C_{D}^{w \alpha}$, $k_{i}$ is the number of edges in or out of node $(i), s_{i}$ is the total weight of the edges in or out of node (i), and $\alpha$ is a tuning parameter that denotes the relative influence of $k$ and $s$. We set $\alpha$ to 0.5 , which gives equal weight to the number and weight of edges at a node (Opsahl et al. 2010).

\section{Results}

Based on our standardization of monthly SST anomalies, we classified 11 years as anomalously cool, nine years as anomalously warm, and 15 years as normal (Fig. 4). Each SST classification was comprised of years spread throughout the time series.

We identified convergence and significant causal interactions between species landings under each SST classification $(p<0.05$; Supplementary Figs. S1, S2 ${ }^{1}$ ). Of the 90 cross-maps we performed (30 for each SST classification), one was excluded because it did not display convergence and a further 14 were excluded for not meeting the seasonal surrogate significance threshold. Many of the relationships we found were bi-directional interactions in which the two species landings causally influenced each other. The interaction networks varied in structure and strength of connections under each SST classification and increased in complexity with increasing temperature (Fig. 5). Many of the relationships we found are likely a result of transitive causation ( $X$ causes $Y, Y$ causes $Z$, therefore $X$ also causes $Z$; Sugihara et al. 2012), making it difficult to disentangle each species to species relationship.

The anomalously warm network had the highest density (0.933), followed by the normal $(0.800)$, and then the anomalously cool networks (0.767). The degree centrality of the nodes varied between the different SST classifications (Fig. 6). The anomalously warm network showed the highest degree centrality overall with all but one outgoing and incoming nodes having a degree centrality greater than 2.0 (Fig. 6). The spread of the degree centrality across nodes was greatest for the anomalously cool (1.08-2.83, $2.13 \pm 0.54$; range, mean \pm SD) and normal networks (1.08-2.82, $2.10 \pm 0.56)$, showing higher variability in the connectedness of nodes than the anomalously warm network (1.58-2.95, $2.56 \pm 0.38)$.

We found that the proportions of total landings made up by each species group varied between SST classifications (Fig. 7). Yellowtail and tuna species made up a larger proportion of total

${ }^{1}$ Supplementary data are available with the article at https://doi.org/10.1139/cjfas-2021-0085. 
Fig. 5. Species landings interaction networks for each SST classification. For all networks the black circles (nodes) denote the species groups: $\mathrm{RF}=$ rockfish species, $\mathrm{KB}=$ kelp bass, $\mathrm{SB}=$ barred sand bass, $\mathrm{BO}=$ Pacific bonito, $\mathrm{YT}=$ yellowtail, $\mathrm{TU}=$ tuna species. The direction and strength of the causal interaction between landings of species groups is shown by the lines connecting the species nodes. Links above the central plane of the nodes indicate causal relationships going from left to right, while links below the central plane denote causal relationships from right to left. The width and transparency of the link indicates the strength of the causal interaction, measured by Pearson's correlation coefficient (rho, $\rho$ ). [Colour online.]

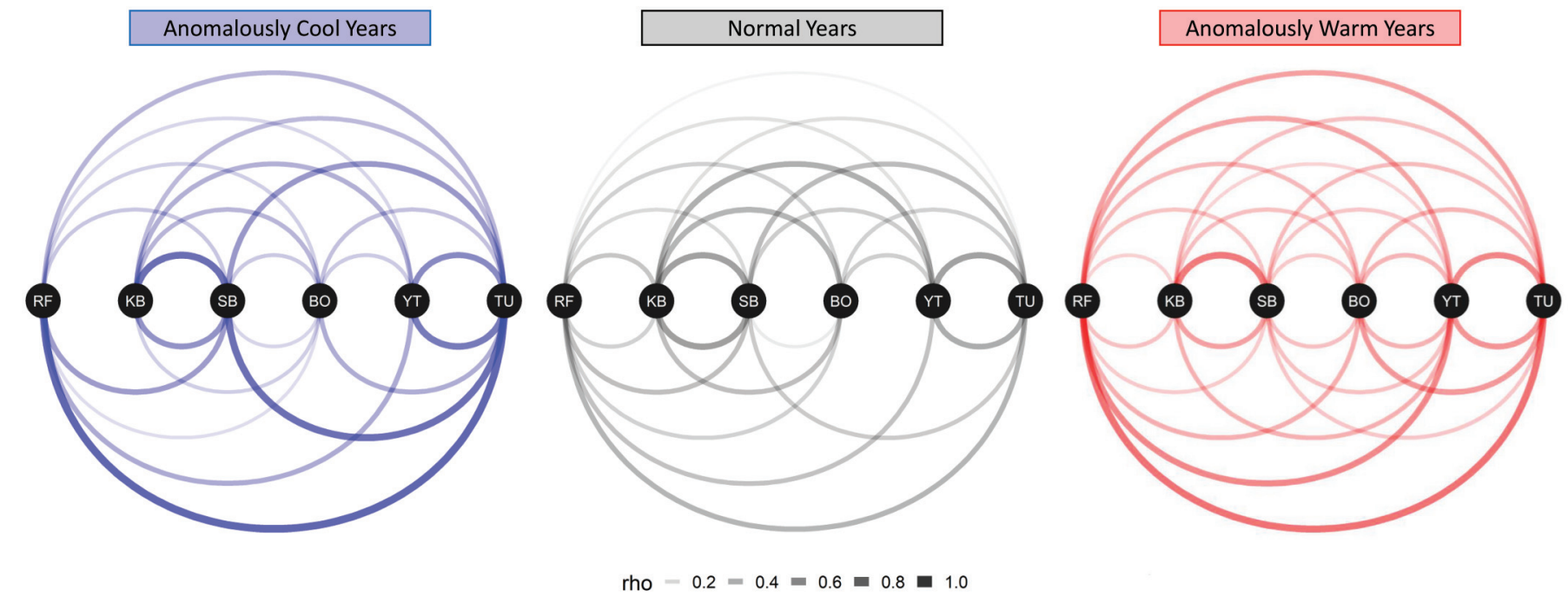

Fig. 6. Violin plot showing the distribution of the degree centrality of all incoming and outgoing nodes in the networks for each of the SST classifications, where the width of the violin corresponds to the distribution of degree centrality values of all nodes. Raw degree centrality values are shown by the black points. [Colour online.]

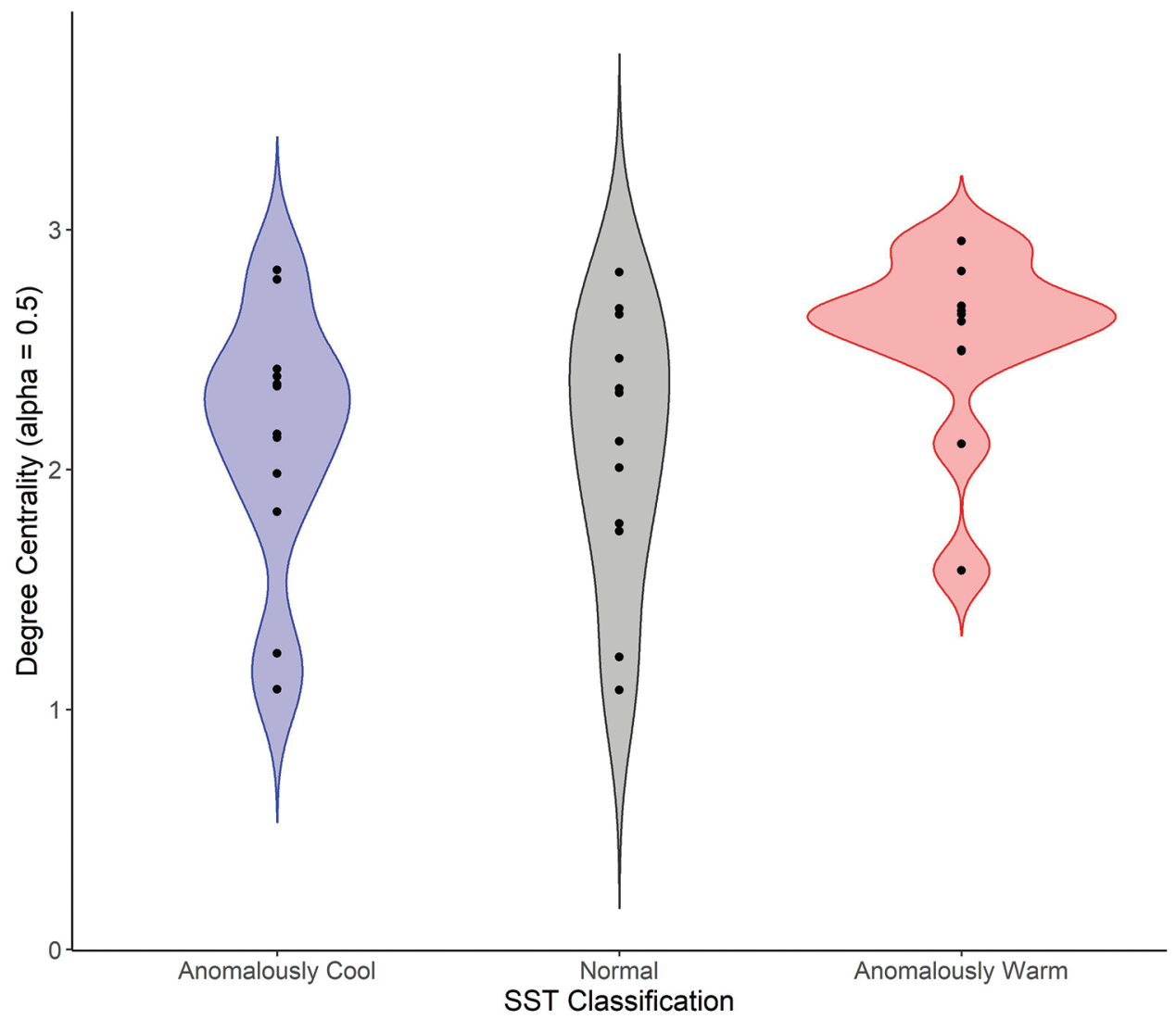


Fig. 7. Proportion of total landings made up by each species group for the different SST classifications for years across the time series (1983-2017). Species groups are shown by different shades of gray: $\mathrm{RF}=$ rockfish species, $\mathrm{KB}=$ kelp bass, $\mathrm{SB}=$ barred sand bass, $\mathrm{BO}=\mathrm{Pacific}$ bonito, $\mathrm{YT}=$ yellowtail. The tuna group is split into a stacked bar of the three species comprising the species group: $\mathrm{AL}=\mathrm{albacore}, \mathrm{BF}=\mathrm{bluefin}$ tuna, $\mathrm{YF}=$ yellowfin tuna. [Colour online.]

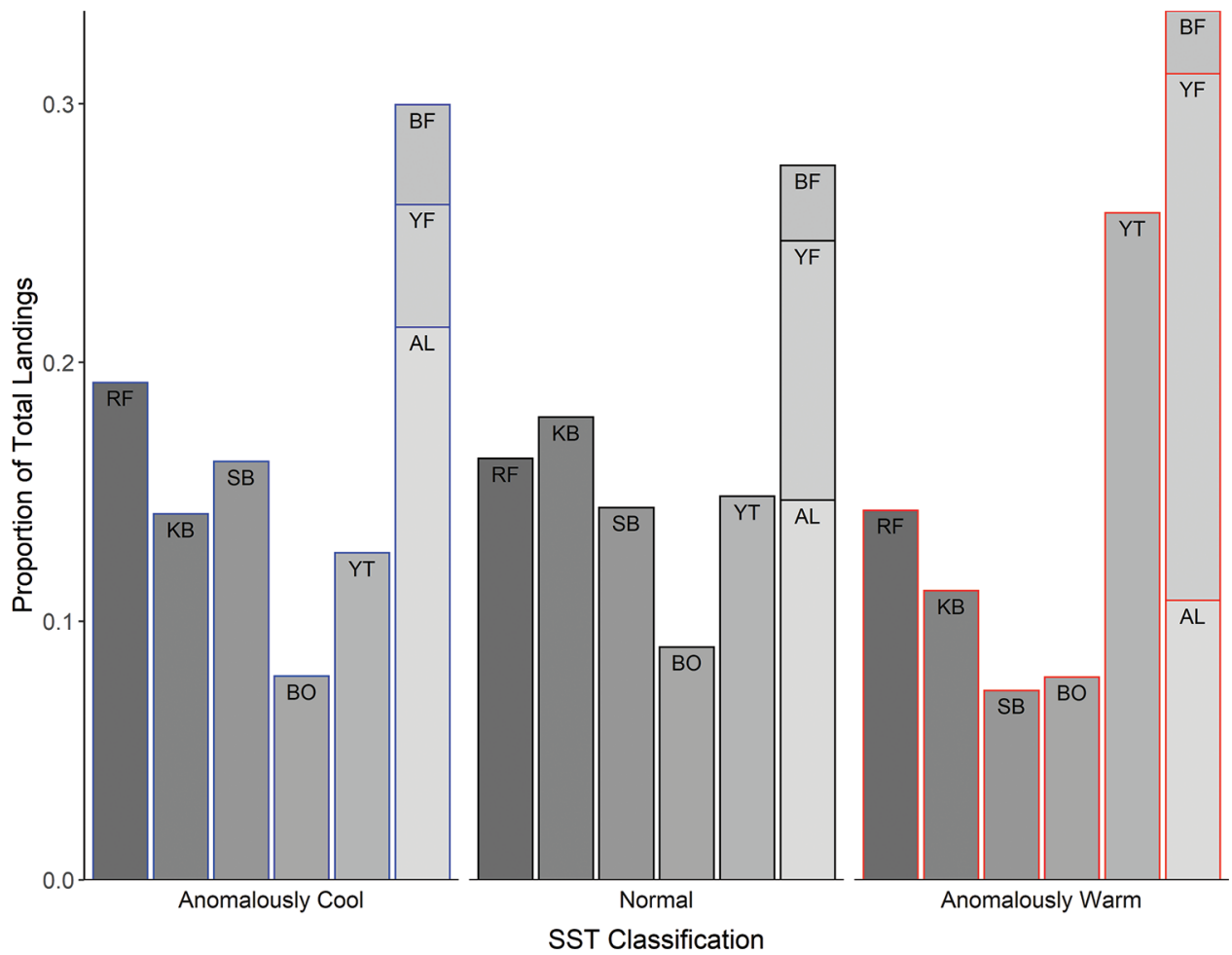

landings with increased SST. Others made up a larger proportion of total landings with decreased SST, such as rockfish species.

\section{Discussion}

Multispecies fisheries constitute complex social-ecological systems that can be difficult to manage, especially given the added challenges associated with climate change. Climate change is causing the world's oceans to warm, and predictions suggest that marine environments will experience a greater frequency of warm SST anomalies in the future (Cai et al. 2014, 2015; Sievanen et al. 2018). This warming impacts fisheries, but the extent and nature of these impacts is not well understood, particularly within multispecies fisheries (Cheung et al. 2013; Perry et al. 2010; Pörtner and Peck 2010; Weatherdon et al. 2016). We used a retrospective analysis to describe underlying causal interaction networks of species landings in a multispecies fishery under different SST scenarios. While many of the individual relationships we found could be deduced based on anecdotal knowledge of our case study fishery, others were more difficult to account for, likely due to being a result of transitive causation. The focus of our study was to use CCM to quantify the structure of the entire network as a function of SST, allowing us to draw conclusions about how the system, as a whole, responds to warming. It is important to note that our "system" is limited to the vessels that we selected for in the CPFV fleet, namely those southern California vessels that target the full suite of our species of interest. Vessels that choose to solely target nearshore or solely target offshore species are likely subject to different underlying landings network conditions. We found causal dependencies between species landings under all SST scenarios, but warmer temperatures were associated with more connected causal interaction networks as shown by higher network density and degree centrality values. Notably, the anomalously warm SST conditions from our analysis mirror regional climate model predictions for the year
2040 (increase of $\sim 0.5$ to $1.5^{\circ} \mathrm{C}$; Sievanen et al. 2018). Increased connectivity of the species landings interaction network under future warm SST conditions will likely increase the risk of unintended consequences from single-species management, as changing the landings of one species will have stronger and more complex cascading effects throughout the landings network. Robust fisheries management in a future warm ocean thus demands the continued development of tools that can account for multispecies interactions.

Studies investigating the response of fisheries to climate change tend to focus on the biological system rather than the human dimensions (Field and Francis 2006; Haynie and Pfeiffer 2012). In this study, we chose to use landings data as the basis of our CCM networks because these data implicitly capture both the ecological dynamics of this fishery and the economic, institutional, and management dynamics. This is especially important in the CPFV socialecological system because the multispecies nature of this fishery creates linkages between species that would not otherwise be connected in a purely ecological context (Dotson and Charter 2003). For example, we found significant causal interactions between rockfish species and tuna species under every SST scenario. These species occupy different habitats, have different life history strategies, and would only interact in the natural environment under the rarest of circumstances. Nevertheless, their landings are linked because they are targeted by the same fishery. One strength of CCM is that it does not necessitate parsing apart the myriad potential drivers of the dynamics of CPFV landings (Sugihara et al. 2012). Because this method allows the data as a whole to direct the results, the networks we constructed are inherently influenced by all the factors that influence the landings themselves.

By splitting our time series based on SST anomalies, we were able to isolate how temperature influences this system, while still allowing for the other socioecological dynamics to operate. One concern with this approach is that filtering our data by SST 
could be confounded by other major shifts in the system, such as technological advances, that occur at the same time, which would result in our spuriously attributing the changes we saw to SST when in fact they were the result of unknown drivers. This is unlikely in our analysis because the years included in each of the SST classifications are dispersed throughout the landings time series and there are no coincident major shifts in the management, environment, or functioning of the CPFV fishery that occurred across all the years represented in each of the SST scenarios. For example, in $2013 \mathrm{CDFW}$ enacted new regulations on the bass species complex (Paralabrax spp.), which raised the size limit from 12 to 14 inches $(1 \mathrm{inch}=2.5 \mathrm{~cm})$ and reduced the bag limit from 10 to 5 individuals (California Code of Regulations Title 14, Section 28.30). While our time series encompasses these changes in regulation, they did not influence our SST network comparisons because our SST classifications include sufficient time periods before and after these changes.

We should note that there are potential pitfalls associated with CCM analysis. In some cases, CCM can generate false positive results that can lead to erroneous conclusions (Bartsev et al. 2021; Cobey and Baskerville 2016). This can occur when time series fluctuate at the same periodicity or when there is not enough data to generate a well-resolved manifold reconstruction (Cobey and Baskerville 2016). Our analysis is not immune to these struggles; however, we made every effort to minimize our susceptibility to them. First, our analysis benefits from being derived from comparatively lengthy time series with high resolution (i.e., daily landings data across 35 years), at least for analyzing seasonality and fisher behavior. Second, we addressed the seasonal nature of our time series by using seasonal surrogate testing to decrease the risk of false positive results resulting from seasonal patterns in the data (Barraquand et al. 2021; Deyle et al. 2016). Barraquand et al. (2021) showed that while this method does not completely remove the risk of false positives, it's inclusion greatly improved the identification of true causal interactions. Placing the results of our CCM in the context of existing knowledge of our study system, we feel confident that the overall trends we found are sound.

CCM requires that the system be effectively stationary and observed over a long enough period to allow for detection of convergence (Sugihara et al. 2012). Our study system is influenced by factors at multiple time scales, and our analysis varies in its ability to address these different scales. On the smallest, subannual scale there is an influence of seasonal factors such as environmental drivers and seasonal regulatory actions, as well as factors that operate on daily or monthly scales, such as fisher behavior. The length of our dataset allows us to capture the dynamics of this subannual scale at high resolution. On the scale of years, longer term biological factors have influence, such as movement of fish populations or recruitment variability. This time scale is less resolved as we only have 35 years of data. Finally, there is the decadal scale, encompassing longer term population dynamics of species and large-scale climate variation, and the dynamics at this scale are even less well-resolved. The potential for seasonal dynamics across these time scales makes the stationarity of the causal interactions questionable. On the other hand, because the response of the CPFV fleet to changing fishery dynamics (e.g., climate induced changes in tuna distributions) is rapid even on weekly time scales, we do not believe lagged fleet responses to changes in the fishery introduce nonstationarity at the time scale of our investigation. In fact, we believe that the subannual dynamics are the most relevant to our analysis because we are dealing with landings data that are ultimately driven by highly responsive fisher behavior. In other words, the most well-resolved time scale captures the relatively rapid response of the fishing community, and by extension landings of different species, to changes in the system, regardless of the time scale of the factors that brought about the changes. While any conclusions about the impacts of climate change on this system have some level of uncertainty, our filtering of landings data under anomalous SST periods allows us to make inferences about the influence of SST on the subannual dynamics of the system.

Based on knowledge of the fishery, we believe that an underlying hierarchical valuation of species targeted by the CPFV fleet is driving the dependencies we observed in our networks. Generally, pelagic species like tunas and yellowtail are more highly valued by the recreational community than other commonly encountered nearshore species such as rockfishes (Dotson and Charter 2003; Parnell et al. 2010). Despite the fact that nearshore species are generally more consistent targets, CPFV captains will often opt to invest resources in traveling farther if there are reports of tuna or yellowtail, especially off San Diego in southern California (Dotson and Charter 2003; Parnell et al. 2010). During anomalously warm years higher value species such as yellowtail become more prevalent (Dotson and Charter 2003). We believe this increased presence of highly valued species accounts for the more complex landings network constructed from anomalously warm years (as shown by the physical structure of the network, higher network density, and higher degree centrality values) because CPFV captains are more regularly making the choice to target these species over more consistent nearshore targets. Anomalously cool and normal years likely have less complex networks because only a subset of the species groups are readily available. This assertion is further reinforced by the greater proportion of landings made up by highvalue, transient species in anomalously warm years. Our analysis quantitatively confirms anecdotal and previously published evidence of the hierarchy of target species among southern California CPFVs (Bellquist et al. 2017; Dotson and Charter 2003; Parnell et al. 2010).

One major concern in predicting fishery responses to climate change is determining the ability of fishery systems to adapt to the unforeseen consequences of a changing ocean (Chavez et al. 2017; Fuller et al. 2017; Perry et al. 2010). Social-ecological resilience can be defined as the ability of a social-ecological system to withstand disturbances while preserving the same basic function (Craig 2017; Folke 2006; Garmestani et al. 2019). The less adaptable a fishery system is, the more vulnerable it is thought to be to perturbation, and therefore the less resilient it is (Chavez et al. 2017; Fuller et al. 2017; Gaines et al. 2018). By explicitly describing the underlying structure of species landings networks under different SST scenarios, our analysis provides an avenue for assessing the resilience of the CPFV fleet to warming ocean conditions. Shifts in the function of the fishery in response to different SST conditions can manifest through differences in the structure of the networks associated with each SST scenario because the networks reflect the connections between landings of species being targeted. The differences in network density and degree centrality between the different SST networks suggest that the CPFV vessels we studied adapted to changing conditions brought on by different SST scenarios. The structural differences in landings networks we observed are likely due to the CPFV fishery's ability to readily adjust to changes in species availability brought on by SST changes. The adaptability of the fishery is in large part due to the flexibility in target species afforded to CPFVs; they can alter their target strategy relatively quickly in response to system changes. For example, in 2001, in apparent response to regulations limiting the catch of rockfish species, the fleet began targeting alternative species like sanddab (Citharichthys spp., Paralichthyidae; Dotson and Charter 2003). Documentation of rapid shifts in the fleet's landings of lower value species (e.g., yellowtail) when higher value species are present (e.g., albacore) further demonstrates this point (Dotson and Charter 2003). Given the adaptability of the fishery and our demonstration that the underlying species landings networks have shifted under different SST conditions in the past, it is likely the southern California CPFVs have stronger resilience to the effects of climate change than other less adaptable fisheries. 
It is difficult to make broad generalizations about the effect of warming SST and climate change on multispecies fisheries; however, our analysis demonstrates that quantifying causal interactions between species landings can be a helpful tool in characterizing fishery-level responses to climate change. A key determinant of changes in network structure and connectivity in our case study was the increased presence of high value transient species during anomalously warm years. Numerous studies have documented fishery species range shifts driven by climate change (e.g., Booth et al. 2011; Gaines et al. 2018; Rogers et al. 2019). Many other multispecies fisheries target species whose presence are mediated by factors affected by climate change, and it is likely that many will experience landings network reorganization in the future as a result. Our findings suggest that the nature of the reorganization will be fishery dependent, based on species-level responses to climate impacts, the underlying preference structure for target species, and the ability of the fishery to adapt to changing conditions. Gaining an understanding of the structure of species landings networks and how the dependencies therein change as a function of climate impacts provides valuable insight into the often unseen interactions in multispecies fisheries that can influence the effectiveness of fisheries management measures.

The CPFV fleet is an important part of the economy, ecosystem, and culture of the southern California region (Bellquist and Semmens 2016; Dotson and Charter 2003; Jarvis et al. 2004; Schroeder and Love 2002). While not comprehensive in its analysis of the potential impacts of climate change, this study provides some guidance as to what can be expected as the CPFV fishery confronts the challenges of a warming ocean. We have shown that years with anomalously warm SST akin to what we can expect as a result of near-term climate change are characterized by more complex and connected networks of species landings. Increased dependencies between species landings are ill-suited for single-species management because management actions meant to regulate the landings of one species can have unforeseen impacts on the landings of other species throughout the network. To support the continued success of the southern California CPFV fleet and multispecies fisheries more broadly in the face of a warming ocean, management agencies need to continue making strides toward implementing multispecies and ecosystem-based approaches.

\section{Competing interests statement}

The authors declare no competing interests.

\section{Funding statement}

The authors declare no specific funding for this work.

\section{Data availability statement}

The CPFV logbook data that support the findings of this study are not publicly available but can be requested from CDFW. The SST data used in this study are freely available from NOAA/OAR/ESRL PSL at https://psl.noaa.gov/.

\section{Acknowledgements}

We thank CDFW for providing access to the CPFV logbook dataset and for providing valuable feedback on this manuscript before submission. We thank NOAA/OAR/ESRL PSL for providing open access SST data. We also acknowledge Chase James, Erica Mason, Noah Ben-Aderet, and Lyall Bellquist for providing insight, critical comments, and suggestions during the analysis and manuscript development process.

\section{References}

Barraquand, F., Picoche, C., Detto, M., and Hartig, F. 2021. Inferring species interactions using Granger causality and convergent cross mapping. Theor. Ecol. 14(1): 87-105. doi:10.1007/s12080-020-00482-7.
Bartsev, S., Saltykov, M., Belolipetsky, P., and Pianykh, A. 2021. Imperfection of the convergent cross-mapping method. IOP Conf. Ser. Mater. Sci. Eng. 1047(1): 012081. doi:10.1088/1757-899X/1047/1/012081.

Becker, R.A., Wilks, A.R., and Brownrigg, R., 2018. Mapdata: extra map databases. R package version 2.3.0. Available from https://CRAN.R-project.org/ package $=$ mapdata.

Bellquist, L., and Semmens, B.X. 2016. Temporal and spatial dynamics of 'trophy'-sized demersal fishes off the California (USA) coast, 1966 to 2013. Mar. Ecol. Prog. Ser. 547: 1-18. doi:10.3354/meps11667.

Bellquist, L., Semmens, B., Stohs, S., and Siddall, A. 2017. Impacts of recently implemented recreational fisheries regulations on the Commercial Passenger Fishing Vessel fishery for Paralabrax sp. in California. Mar. Pol. 86: 134-143. doi:10.1016/j.marpol.2017.09.017.

Booth, D.J., Bond, N., and Macreadie, P. 2011. Detecting range shifts among Australian fishes in response to climate change. Mar. Freshwater Res. 62(9): 1027-1042. doi:10.1071/MF10270.

Cai, W., Borlace, S., Lengaigne, M., Van Rensch, P., Collins, M., Vecchi, G., et al. 2014. Increasing frequency of extreme El Niño events due to greenhouse warming. Nat. Clim. Chang. 4(2): 111-116. doi:10.1038/nclimate2100.

Cai, W., Wang, G., Santoso, A., McPhaden, M.J., Wu, L., Jin, F.-F., et al. 2015. Increased frequency of extreme La Niña events under greenhouse warming. Nat. Clim. Chang. 5(2): 132-137. doi:10.1038/nclimate2492.

Caminade, C., McIntyre, K.M., and Jones, A.E. 2019. Impact of recent and future climate change on vector-borne diseases. Ann. N.Y. Acad. Sci. 1436(1): 157-173. doi:10.1111/nyas.13950. PMID:30120891.

Campbell, B.M., Vermeulen, S.J., Aggarwal, P.K., Corner-Dolloff, C., Girvetz, E., Loboguerrero, A.M., et al. 2016. Reducing risks to food security from climate change. Glob. Food Security, 11: 34-43. doi:10.1016/j.gfs.2016.06.002.

Chavez, F.P., Costello, C., Aseltine-Neilson, D., Doremus, H., Field, J.C., Gaines, S.D., et al. 2017. Readying California fisheries for climate change. California Ocean Science Trust, Oakland, Calif.

Cheung, W.W.L., Watson, R., and Pauly, D. 2013. Signature of ocean warming in global fisheries catch. Nature, 497(7449): 365-368. doi:10.1038/nature12156. PMID:23676754.

Cobey, S., and Baskerville, E.B. 2016. Limits to causal inference with statespace reconstruction for infectious disease. PLOS ONE, 11(12): e0169050. doi:10.1371/journal.pone.0169050. PMID:28030639.

Craig, R.K. 2017. Putting resilience theory into practice: the example of fisheries management. Nat. Resour. Environ. 31(3): 3-7.

Deyle, E.R., and Sugihara, G. 2011. Generalized theorems for nonlinear state space reconstruction. PLoS ONE, 6(3): e18295. doi:10.1371/journal. pone.0018295. PMID:21483839.

Deyle, E.R., Maher, M.C., Hernandez, R.D., Basu, S., and Sugihara, G. 2016. Global environmental drivers of influenza. Proc. Natl. Acad. Sci. U.S.A. 113(46): 13081-13086. doi:10.1073/pnas.1607747113. PMID:27799563.

Dotson, R., and Charter, R. 2003. Trends in the Southern California sport fishery. California Cooperative Oceanic Fisheries Investigations Report. pp. 94-106.

Field, J.C., and Francis, R.C. 2006. Considering ecosystem-based fisheries management in the California current. Mar. Pol. 30(5): 552-569. doi:10.1016/j.marpol. 2005.07.004.

Folke, C. 2006. Resilience: the emergence of a perspective for social-ecological systems analyses. Glob. Environ. Chang. 16: 253-267. doi:10.1016/j.gloenvcha. 2006.04.002

Free, C.M., Thorson, J.T., Pinsky, M.L., Oken, K.L., Wiedenmann, J., and Jensen, O.P. 2019. Impacts of historical warming on marine fisheries production. Science, 363(6430): 979-983. doi:10.1126/science.aau1758. PMID:30819962.

Fuller, E.C., Samhouri, J.F., Stoll, J.S., Levin, S.A., and Watson, J.R. 2017. Characterizing fisheries connectivity in marine social-ecological systems. ICES J. Mar. Sci. 74(8): 2087-2096. doi:10.1093/icesjms/fsx128.

Gaines, S.D., Costello, C., Owashi, B., Mangin, T., Bone, J., Molinos, J.G., et al. 2018. Improved fisheries management could offset many negative effects of climate change. Sci. Adv. 4(8): eaao1378. doi:10.1126/sciadv.aao1378. PMID: 30167455

Garmestani, A., Craig, R.K., Gilissen, H.K., McDonald, J., Soininen, N., van Doorn-Hoekveld, W.J., and van Rijswick, H.F.M.W. 2019. The role of socialecological resilience in coastal zone management: a comparative law approach to three coastal nations. Front. Ecol. Evol. 7: 410. doi:10.3389/fevo.2019.00410.

Haynie, A.C., and Pfeiffer, L. 2012. Why economics matters for understanding the effects of climate change on fisheries. ICES J. Mar. Sci. 69(7): 1160-1167. doi:10.1093/icesjms/fss021.

Hill, K.T., and Barnes, J.T. 1998. Historical catch data from California's commercial passenger fishing vessel fleet: status and comparison of two sources. Marine Region Technical Report Number 60. California Department of Fish and Game, Sacramento, Calif.

Jarvis, E.T., Allen, M.J., and Smith, R.W. 2004. Comparison of recreational fish catch trends to environment-species relationships and fishery-independent data in the southern California bight, 1980-2000. CalCOFI Rep., Vol. 45. California Cooperative Oceanic Fisheries Investigations. pp. 167-179.

Jarvis, E.T., Gliniak, H.L., and Valle, C.F. 2014. Effects of fishing and the environment on the long-term sustainability of the recreational saltwater bass fishery in southern California. Calif. Fish Game, 100(2): 234-259.

Kukal, M.S., and Irmak, S. 2018. Climate-driven crop yield and yield variability and climate change impacts on the U.S. Great Plains agricultural production. Sci. Rep. 8(1): 3450. doi:10.1038/s41598-018-21848-2. PMID:29472598. 
Miller, K., Charles, A., Barange, M., Brander, K., Gallucci, V.F., Gasalla, M.A., et al. 2010. Climate change, uncertainty, and resilient fisheries: institutional responses through integrative science. Prog. Oceanogr. 87(1): 338-346. doi:10.1016/j.pocean.2010.09.014.

Murawski, S.A. 1991. Can we manage our multispecies fisheries? Fisheries, 16(5): 5-13. doi:10.1577/1548-8446(1991)016<0005:CWMOMF >2.0.CO;2.

Nielsen, J.R., Thunberg, E., Holland, D.S., Schmidt, J.O., Fulton, E.A., Bastardie, F., et al. 2018. Integrated ecological-economic fisheries modelsevaluation, review and challenges for implementation. Fish Fish. 19(1): 1-29. doi:10.1111/faf.12232.

Opsahl, T., Agneessens, F., and Skvoretz, J. 2010. Node centrality in weighted networks: generalizing degree and shortest paths. Soc. Networks, 32: 245251. doi:10.1016/j.socnet.2010.03.006.

Parnell, P.E., Dayton, P.K., Fisher, R.A., Loarie, C.C., and Darrow, R.D. 2010. Spatial patterns of fishing effort off San Diego: implications for zonal management and ecosystem function. Ecol. Appl. 20(8): 2203-2222. doi:10.1890 09-1543.1. PMID:21265452.

Perry, R.I., Ommer, R.E., Allison, E.H., Badjeck, M.-C., Barange, M., Hamilton, L., et al. 2010. Interactions between changes in marine ecosystems and human communities. In Marine Ecosystems and Global Change. Oxford University Press, Oxford, UK. pp. 221-252. doi:10.1093/acprof:oso/9780199558025. 001.0001.

Plagányi, É.E., Punt, A.E., Hillary, R., Morello, E.B., Thébaud, O., Hutton, T., et al. 2014. Multispecies fisheries management and conservation: tactical applications using models of intermediate complexity. Fish Fish. 15(1): 1-22. doi:10.1111/j.1467-2979.2012.00488.x.

Pörtner, H.O., and Peck, M.A. 2010. Climate change effects on fishes and fisheries: towards a cause-and-effect understanding. J. Fish Biol. 77(8): 1745-1779. doi:10.1111/j.1095-8649.2010.02783.x.

Proulx, S.R., Promislow, D.E.L., and Phillips, P.C. 2005. Network thinking in ecology and evolution. Trends Ecol. Evol. 20(6): 345-353. doi:10.1016/j. tree.2005.04.004. PMID:16701391.

R Core Team. 2019. R: a language and environment for statistical computing. R Foundation for Statistical Computing, Vienna, Austria.

Rayner, N.A.A., Parker, D.E., Horton, E.B., Folland, C.K., Alexander, L.V., Rowell, D.P., et al. 2003. Global analyses of sea surface temperature, sea ice, and night marine air temperature since the late nineteenth century. J. Geophys. Res. 108(D14). doi:10.1029/2002JD002670.

Reynolds, R.W., Smith, T.M., Liu, C., Chelton, D.B., Casey, K.S., and Schlax, M.G. 2007. Daily high-resolution-blended analyses for sea surface temperature. J. Clim. 20(22): 5473-5496. doi:10.1175/2007JCLI1824.1.

Rogers, L.A., Griffin, R., Young, T., Fuller, E., Martin, K.S., and Pinsky, M.L. 2019. Shifting habitats expose fishing communities to risk under climate change. Nat. Clim. Chang. 9(7): 512-516. doi:10.1038/s41558-019-0503-z.
Schroeder, D.M., and Love, M.S. 2002. Recreational fishing and marine fish populations in California. CalCOFI Rep. Vol. 43. California Cooperative Oceanic Fisheries Investigations (CalCOFI). pp. 182-190.

Sievanen, L., Phillips, J., Colgan, C., Griggs, G., Finzi Hart, J., Hartge, E., et al. 2018. California's coast and ocean summary report. SUMCCC4A2018-011. California's Fourth Climate Change Assessment.

Sugihara, G., and May, R.M. 1990. Nonlinear forecasting as a way of distinguishing chaos from measurement error in time series. Nature, 344(6268): 734-741. doi:10.1038/344734a0. PMID:2330029.

Sugihara, G., May, R., Ye, H., Hsieh, C., Deyle, E., Fogarty, M., and Munch, S. 2012. Detecting causality in complex ecosystems. Science, 338(6106): 496500. doi:10.1126/science.1227079. PMID:22997134.

Takens, F. 1981. Detecting strange attractors in turbulence. In Dynamical Systems and Turbulence, Warwick 1980. Edited by D. Rand and L. Young. Lecture Notes in Mathematics, Vol. 898. Springer Verlag. pp. 366-381.

Thorpe, R.B., Dolder, P.J., Reeves, S., Robinson, P., and Jennings, S. 2016. Assessing fishery and ecological consequences of alternate management options for multispecies fisheries. ICES J. Mar. Sci. 73(6): 1503-1512. doi:10.1093/icesjms/ fsw028.

Ulrich, C., Reeves, S.A., Vermard, Y., Holmes, S.J., and Vanhee, W. 2011. Reconciling single-species TACs in the North Sea demersal fisheries using the Fcube mixed-fisheries advice framework. ICES J. Mar. Sci. 68(7): 15351547. doi:10.1093/icesjms/fsr060.

Ushio, M., Hsieh, C., Masuda, R., Deyle, E.R., Ye, H., Chang, C.-W., et al. 2018. Fluctuating interaction network and time-varying stability of a natural fish community. Nature, 554(7692): 360-363. doi:10.1038/nature25504. PMID:29414940.

Vinther, M., Reeves, S.A., and Patterson, K.R. 2004. From single-species advice to mixed-species management: taking the next step. ICES J. Mar. Sci. 61(8): 1398-1409. doi:10.1016/j.icesjms.2004.08.018.

Weatherdon, L.V., Magnan, A.K., Rogers, A.D., Sumaila, U.R., and Cheung, W.W.L. 2016. Observed and projected impacts of climate change on marine fisheries, aquaculture, coastal tourism, and human health: an update. Front. Mar. Sci. 3: 48. doi:10.3389/fmars.2016.00048.

Weber, M.L., and Heneman, B. 2000. Guide to California's marine life management act. Common Knowledge Press, Bolinas, Calif.

Wu, X., Lu, Y., Zhou, S., Chen, L., and Xu, B. 2016. Impact of climate change on human infectious diseases: empirical evidence and human adaptation. Environ. Int. 86: 14-23. doi:10.1016/j.envint.2015.09.007. PMID:26479830.

Ye, H., Deyle, E.R., Gilarranz, L.J., and Sugihara, G. 2015. Distinguishing time-delayed causal interactions using convergent cross mapping. Sci. Rep. 5: 14750. doi:10.1038/srep14750. PMID:26435402.

Ye, H., Clark, A., Deyle, E., and Munch, S. 2021. rEDM: applications of empirical dynamic modeling from time series. In ha0ye/rEDM: Applications of Empirical Dynamic Modeling from Time Series. Available from https:/| rdrr.io/github/ha0ye/rEDM/man/rEDM.html. 